Archives

$4 \mid 1989$

Varia

\title{
Notre ami Denis Richet (1927-1989)
}

\section{Robert Descimon}

\section{(apenEdition \\ Journals}

\section{Édition électronique}

URL : http://journals.openedition.org/ccrh/2915

DOI : $10.4000 /$ ccrh.2915

ISSN : 1760-7906

\section{Éditeur}

Centre de recherches historiques - EHESS

\section{Édition imprimée}

Date de publication : 15 octobre 1989

ISSN : 0990-9141

\section{Référence électronique}

Robert Descimon, « Notre ami Denis Richet (1927-1989) », Les Cahiers du Centre de Recherches Historiques [En ligne], 4 | 1989, mis en ligne le 13 avril 2009, consulté le 07 mai 2019. URL : http:// journals.openedition.org/ccrh/2915; DOI : 10.4000/ccrh.2915

Ce document a été généré automatiquement le 7 mai 2019.

Article L.111-1 du Code de la propriété intellectuelle. 


\title{
Notre ami Denis Richet (1927-1989)
}

\author{
Robert Descimon
}

1 Le Centre de recherches historiques comptait pour beaucoup dans la vie de Denis Richet: il le fréquentait comme un vrai domicile professionnel, comme le cœur d'une institution qu'il aimait, comme un lieu de familiarité et d'amitié aussi.

2 Denis avait, quelques mois, assuré la direction du Centre où il aimait à croire que régnait toujours l'esprit fondateur de Fernand Braudel. Denis était homme de fidélité, y compris à une certaine conception de l'histoire. Une fidélité qui excluait toute révérence à la tradition, mais savait la force des réflexions héritées et repensées, des réflexions sur le temps long aussi... Il n'attachait pas d'importance aux modes, aux détails érudits, ni aux idéologies, mais il était un historien ami des archives et des exigences théoriques. « Aimer l'histoire pour elle-même », disait-il, et ainsi il pratiquait.

3 L'œuvre de Denis Richet, inséparable de son enseignement, se concentre sur deux temps forts de la formation de la France : la Révolution et l'époque des guerres de Religion et de la Contre-Réforme jusqu'à la Fronde. Ce double regard fécondait l'un et l'autre champ de recherche et fondait l'originalité rare de sa pensée. D'autres en ont parlé mieux que je pourrais le faire. Je citerai simplement sa thèse encore inédite Les Séguier avant le chancelier (1964) et L'esprit des institutions (1973), livre novateur et toujours aussi neuf. On découvre et on découvrira des analyses saisissantes en parcourant ses articles, parus ou à paraitre, dont il voulait former un recueil remis à Flammarion. C'est pour ses amis une obligation impérieuse que de faire aboutir l'entreprise.

4 A la Sorbonne et à Tours, il avait été un enseignant heureux : l'exigence qu'il avait pour lui-même - les magnifiques manuscrits de ses cours en témoignent-, il avait su en transmettre l'idéal à ses élèves. A la Sixième Section, comme elle s'appelait alors, il donna son entière mesure de professeur hors pair et de chercheur à l'esprit limpide. Il fut l'inspirateur des études sérielles sur les Mazarinades et sur les textes, cahiers de doléances et pamphlets, que suscitèrent les Etats généraux de 1614 (voir le livre de Roger Chartier et Denis Richet, Représentation et vouloir politiques. Autour des Etats généraux de 1614, paru en 1982). Surtout, il lança les enquêtes sur la notabilité parisienne du XVI ${ }^{\mathrm{e}}$ et du XVII siècle: aspects sociaux, économiques, civiques, religieux..., rien n'était laissé dans l'ombre à partir du registre du «don gratuit» de 1571, des archives municipales, 
notariales et paroissiales. L'essentiel des résultats attend encore publication, mais nous sommes quelques-uns à nous remémorer des séminaires inoubliables.

5 Car le plus important pour Denis, ce fut l'enseignement de la recherche. Le séminaire se tint le mercredi rue de Varenne, au bas du boulevard Raspail (une salle bien froide l'hiver), rue de la Tour, puis le mardi, salle 524, et boulevard Saint-Michel. S'y réunissait aux origines un petit groupe de chercheurs passionnés. Par la suite l'auditoire, vivant autour de multiples centres d'intérêt, regroupait collègues, étudiants et amateurs, Français et Etrangers, permanents et occasionnels, au gré des emplois du temps, des années sabbatiques et des thématiques renouvelées. Le séminaire fut un lieu d'échanges, de libre parole et d'écoute mutuelle, dans une même communion pour l'histoire. C'est cela que le Centre et l'Ecole ont perdu. Denis Richet n'était avare ni de ses idées, ni de ses archives. Toujours il resta la cheville ouvrière et l'âme de l'équipe que son charisme scientifique avait créée. Pour nous tous, ses amis à qui il a été donné de partager son travail, sa mort représente une perte cruelle, un vide que rien ne viendra combler. Ces mots sont banals, mais ils sont vrais.

Le téléphone ne sonne plus le soir. Là, dans le couloir du Centre, une silhouette, un chapeau, une démarche, une voix qui n'ont pas cessé d'être familiers... Et puis, dans notre souvenir parfois douloureux, cet anticonformisme qui était sa façon d'être au monde. 